\title{
Decision Support System for Islamic Couple Selection Using Fuzzy-AHP and WSM Method Based Web
}

\author{
Yulian Findawati ${ }^{1}$, Nadifatul Qomariyah $^{1}$, Arif Senja Fitroni $^{1}$, and Dahlan Abdullah ${ }^{2}$ \\ ${ }^{1}$ Universitas Muhammadiyah Sidoarjo, Department of Informatics, East Java, Indonesia \\ ${ }^{2}$ Universitas Malikussaleh, Department of Informatics, Aceh, Indonesia
}

\begin{abstract}
So far in Islamic marriage done by ta'aruf process which is the initial process of introduction in marriage. Therefore, the election system of Islamic couple is chosen to make it easier for couples to get the best partner for themselves. This system aims to provide partner recommendations with multiple options. Measurement in matchmaking using Fuzzy-Analytical Hierarchy Process (Fuzzy-AHP) and Weighted Sum Model (WSM) method because the basic concept of F-AHP method is a method used to know the action performed by comparison between several factors and some alternatives. FAHP is used in criteria weighting and WSM is used in sub criteria weighting. The results of weighting of each alternative in accordance with many criteria established, namely religion, property, heredity, physical, education, organization, marital status, expertise, and rank. The study compared the use of FAHP and WSM methods compared with AHP and WSM methods. And the result is Using AHP, found that Religion has the highest priority that is 0.4073 while using FAHP has the highest priority that is religion, organization, expertise, status, and rank with weight 0.172848 . As for the results of alternative rankings, the use of fuzzy-AHP method is closer to the recommendation given by AHP.
\end{abstract}

\section{Introduction}

The development of advances in information technology is needed in various fields, then from that create a system that can help in improving the effectiveness of results and efficiency, or business individual or company, not least Higher Education or Education World. Many people use information technology to look for things that are personal, such as searching or matchmaking. So far in an Islamic marriage is done by ta'aruf process that is the initial process of introduction that choose to marry. In general, the process is done by exchange of biodata between men and women who are accompanied by parents, close family, friends, tutoring teachers or dating agency. During this time the decision of the election of Islamic couples is done manually by considering the decision of the family, or ustadz / ustadzah. Therefore, the researcher makes the decision support system of recommendation of the selection of Islamic pair using fuzzy-AHP and WSM method as an effort to assist the individual in determining their partner based on the criteria of Islamic couple.

Therefore, the researcher makes a decision support system that can help Islamic couple selection recommendation. Researchers can do research in the search for a mate using the method of Fuzzy-Analytical Hierarchy Process (F-AHP) because the basic concept of Fuzzy- AHP method is the method used to find the right alternative. FAHP is implemented in different fields as follows Supplier selection [1], Learning Management System Selection [2]. Comparative Analysis between Fuzzy and traditional Analytical Hierarchy Process [3], Assessment Model of National Grants of University using FAHP [4], Determining e learning success factor in higher education based on user perspective using Fuzzy AHP [5] and Evaluation of Elevator Based on F-AHP [6]. F-AHP method will give weighted results of each alternative in accordance with many established criteria, i.e. religion, property, heredity, physical, education, organization (societal), marital status, expertise, and rank. While for the calculation of sub criteria using Weighted Sum Model Method. This system aims to provide partner recommendations with multiple options. Measurement in matchmaking using Fuzzy-Analytical Hierarchy Process (Fuzzy-AHP) and Weighted Sum Model (WSM) method because the basic concept of F-AHP method is a method used to know the action performed by comparison between several factors and some alternatives. In addition, in this paper a comparison will be made between two methods (AHP and FAHP), to highlight the effects of linguistic assessment on decisions. This system is built using the web to be provided by others. Based on the problems that exist then the main issues as follows:

- How to solve couples' selection using the FuzzyAnalytical Hierarchy Process (F-AHP) and WSM method?

\footnotetext{
* Corresponding author: yulianfindawati@umsida.ac.id
} 
- How to compare the Fuzzy-Analytical Hierarchy Process (F-AHP) and AHP method?

\section{Literature review}

\subsection{Definition of decision and SPK}

According to Keen and Scoot Morton [7] Decision Support System (SPK) is an intellectual partner of human resources with the ability of computers to improve the quality of decisions, namely computerbased support systems for management decision makers to deal with semi-structured problems.

\subsection{Fuzzy-AHP}

Fuzzy-AHP is an efficient tool for handling the obscurity of data in deciding the choices of different decision variables. Comparisons are represented in triangular fuzzy numbers to build a fuzzy pairwise matrix comparison [8].

\subsection{The Islamic couple}

The Islamic couple are couples who fit the criteria from the religious point of view such as: Pray 5 times, Sunnah Prayer, Recite the Qur'an, Compulsory fasting, Fasting Sunnah, Activity in Islamic activities, etc. What needs to be attention is that things that can make the slander can be avoided by both parties such as communicating by phone, SMS, wad another social media with a reason to ta'aruf with a potential partner.

\section{Result and discussion}

\subsection{Fuzzy- AHP and Weighted sum models' calculation}

The FAHP technique is a highly developed analytical method from the AHP. Generally, imprecise judgments are used rather than precise judgments in daily life. In FAHP, crisp values of the decision makers are expressed as fuzzy comparison sets (fuzzy triangular numbers). It uses derivative fuzzy ratios instead of crisp priorities in AHP because decision maker preferences in AHP are based on perception but the FAHP is more representative for decisions of humans. Due to these reasons, FAHP is used as a MCDM method in our study in the selection of Islamic Couples it consists of 9 criteria which weighting using AHP fuzzy while the weighting sub criteria will use the weighted sum models. The criteria and sub criteria can be seen in Figure 1.

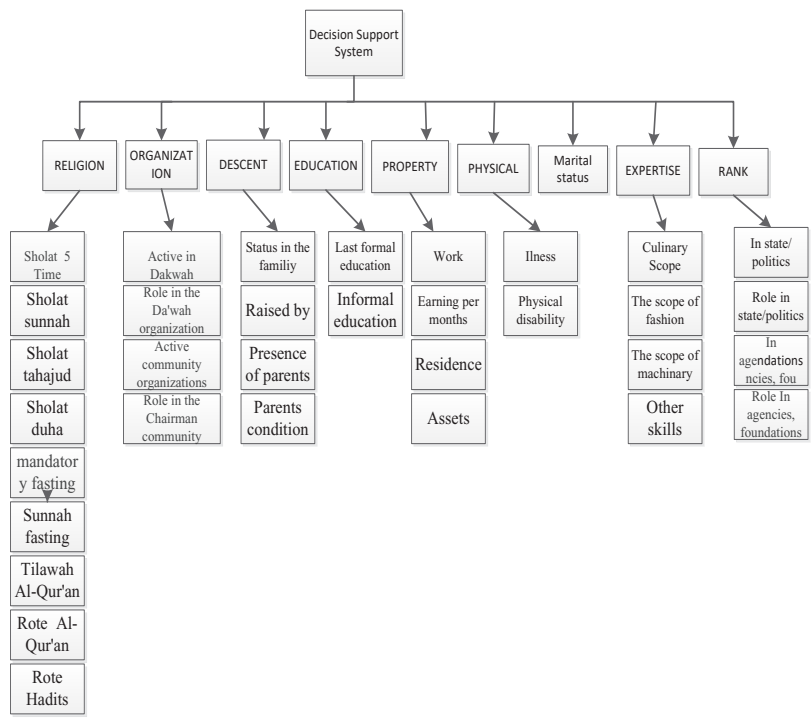

Fig. 1. Criteria and sub criteria.

Criteria consist of Religion, Organization, Descent, Education, Property, Physical, Marital Status, Expertise, and rank. The data are obtained from the interview with ustadz and Results of questionnaire youth of Al-Falah mosque Jogosari Pandaan. Three alternatives have been identified as potential Islamic pairs. The main objective is to select the best Islamic pairs that satisfies all criteria. The solution process is based on the fuzzy AHP method and weighted sum models. Table of importance level can be seen in table 1 .

Table 1. Table Level of importance criteria based on Fuzzy-AHP method.

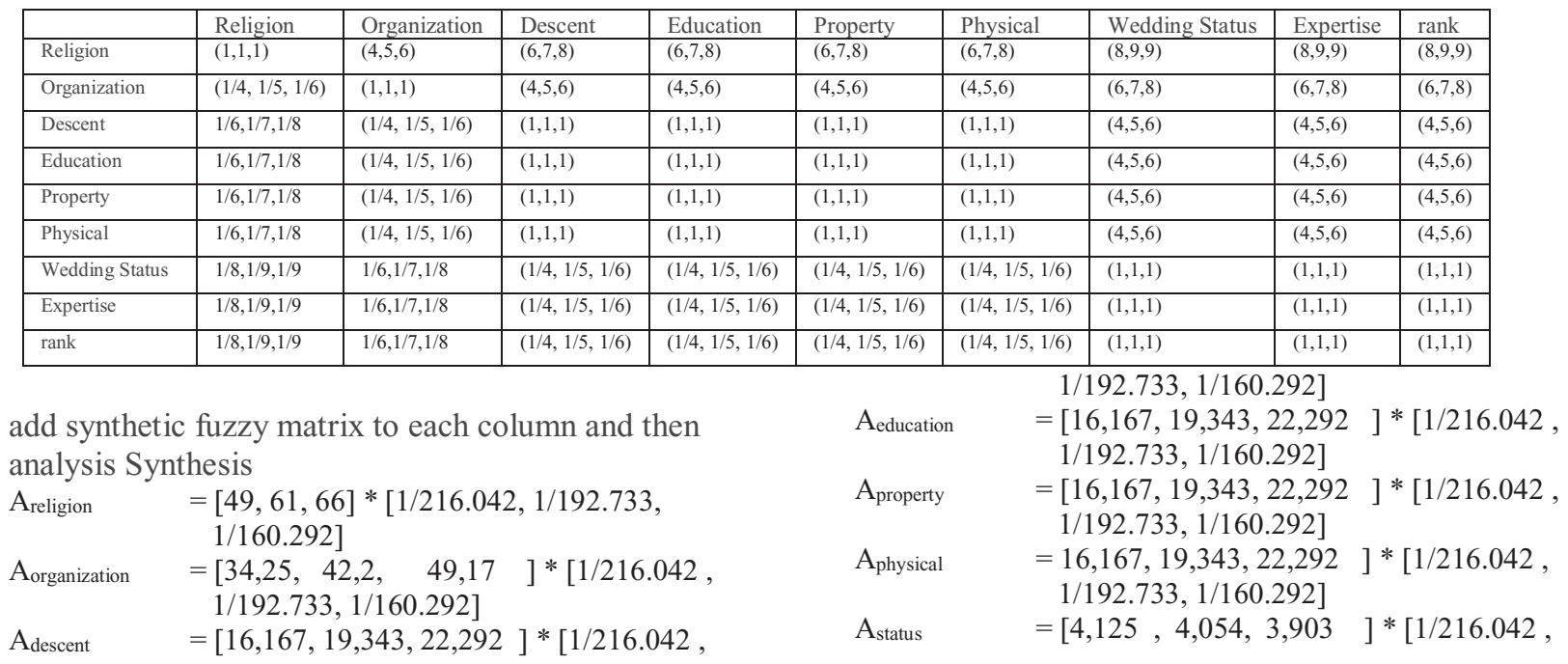




$$
\begin{aligned}
& 1 / 192.733,1 / 160.292] \\
& \text { Aexpertise } \quad=[4,125,4,054,3,903] *[1 / 216.042 \text {, } \\
& 1 / 192.733,1 / 160.292] \\
& \mathrm{A}_{\mathrm{rank}} \quad=[4,125,4,054,3,903] *[1 / 216.042, \\
& 1 / 192.733,1 / 160.292] \\
& =[0.227,0.316,0.412] \\
& =[0.159,0.219,0.307] \\
& =[0.075,0.1,0.139] \\
& =[0.075,0.1,0.139] \\
& =[0.075,0.1,0.139] \\
& =[0.075,0.1,0.139] \\
& =[0.019,0.021,0.024] \\
& =[0.019,0.021,0.024] \\
& =[0.019,0.021,0.024]
\end{aligned}
$$

- Calculate the degree of probability and Calculating priority Weight

$$
\begin{aligned}
& \mathrm{d}^{\prime}(\text { Religion }) \quad=\min (1,1,1,1,1,1,1,1)=1 \\
& \mathrm{~d}^{\prime}(\text { Organization })=\min (1.53,1,1,1,1,1,1,1)=1 \\
& \mathrm{~d}^{\prime}(\text { Descent }) \quad=\min (0.68332,0.19636,1 \text {, } \\
& , 1,1,1,1,1)=0.19636 \\
& \mathrm{~d}^{\prime}(\text { Education })=\min (0.68332,0.19636,1,1,1,1,1,1) \\
& =0.19636 \\
& \mathrm{~d}^{\prime}(\text { Property })=\min (0.68332,0.19636,1,, 1,1,1,1,1) \\
& =0.19636 \\
& \mathrm{~d}^{\prime}(\text { Physical })=\min (0.68332,0.19636,1,, 1,1,1,1,1) \\
& =0.19636 \\
& \mathrm{~d}^{\prime}(\text { Status }) \quad=\min (2.17687,2.10538,1.97745, \\
& 1.97745,1.97745,2.93117,1,1)=1 \\
& \mathrm{~d}^{\prime}(\text { Expertise })=\min (2.17687,2.10538,1.97745 \text {, } \\
& 1.97745,1.97745,2.93117,1,1)=1 \\
& \mathrm{~d}^{\prime}(\text { rank }) \quad=\min (2.17687,2.10538,1.97745 \text {, } \\
& 1.97745,1.97745,2.93117,1,1)=1
\end{aligned}
$$

- Normalization of vector weight

$\mathrm{W}^{\prime}=(0.172848 ; 0.172848 ; 0.03394 ; 0.03394$;

$0.03394 ; 0.03394 ; 0.172848$;

$$
0.172848 ; 0.172848)
$$

Each criterion each has sub criteria in the form of questions that will be answered by the user then calculated the weight. The calculation of sub criteria using Weighted Sum Model method. WSM is most commonly used approach in single dimensional problems [9]. If there are alternatives $m$ and $n$ criteria, then according to the best alternative can be formulated as follows:

$$
A_{i}^{\text {WSMScore }}=\sum_{j=1}^{n} w_{j} a_{i j}, \text { for } i=1,2,3, \cdots, m
$$

where $\mathrm{i}=1,2,3, \Lambda, \mathrm{m}$ is the value of the best alternative, $\mathrm{n}$ is the number of criteria, an alternative value $i$ the criteria $j$, are value criteria $j$ and max used to sort the alternative decision.

The calculation of the total value sub criteria based on the answers sub criteria candidate Islamic pair then multiplied by the weight sub criteria based on the data above is as follows:

Total value Religious sub criteria $=(0.182 * 0.667)+$ $(0.909 * 0.667)+(0.909 * 0.667)+(0.909 * 0.667)+$
$(0.909 * 0.333)+(0.909 * 0.667)+(0.909 \times 0.333)+$ $((0.909 * 0.333)=0.545$

total value organization Subcriteria $=0.745741$

total value descent Subcriteria $=0.583333$

total value education Subcriteria $=0.358857$

total value property Subcriteria $=0.380392$

total value physical Subcriteria $=0.666667$

total value expertise Subcriteria $=0.166667$

total value rank Subcriteria $=0,020833$

After obtaining the total value of sub criteria it will be multiplied by the weight of fuzzy-AHP criteria so that the final calculation of total decision is obtained. Calculations can be done as follows:

The total value of the alternative decision $\mathrm{A}=(0.545$ $* 1)+(0.58333 * 0.19636)+(0.358857 * 0.19636)+$ $(0.6667 * 0.19636))+(0 * 1)+(0.16667)+((0.020833 *$ 1) $=1.869$

Based on the same calculation then obtained the total value of the alternative decision $\mathrm{B}=1.843769$ and the total value of the alternative decision $\mathrm{C}=1.573106$. After obtaining the total alternative decision then done ranking based on the total value of the decision, it is found that the candidate Islamic partner recommended is A.

In this study also compared fuzzy AHP and AHP weighting with the same importance level. The comparison of the results of AHP and Fuzzy AHP weight calculation can be seen in figure 2

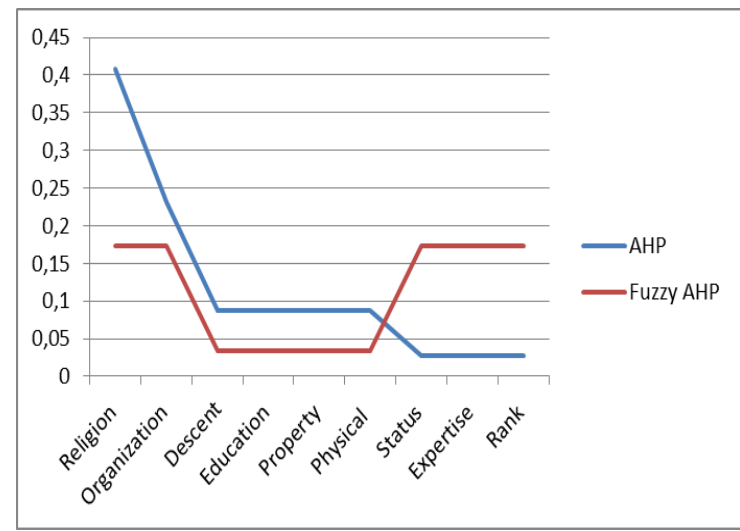

Fig. 2. AHP and AHP fuzzy weighted comparison.

Using AHP, found that Religion has the highest priority that is 0.4073 while using FAHP has the highest priority that is religion, organization, expertise, status, and rank with weight 0.172848

In this study also compared fuzzy-AHP and AHP in the same case, the comparison results of ranking calculation based on AHP and WSM with ranking calculation based on Fuzzy AHP and WSM can be seen in table 2 .

Table 2. Results rank alternative.

\begin{tabular}{|l|c|c|c|}
\hline \multirow{2}{*}{ Number } & \multicolumn{3}{|c|}{ Results Rank Alternative } \\
\cline { 2 - 4 } & $\begin{array}{l}\text { Fuzzy AHP and } \\
\text { WSM }\end{array}$ & $\begin{array}{l}\text { AHP and } \\
\text { WSM }\end{array}$ & $\begin{array}{l}\text { Expert } \\
\text { Recommendation }\end{array}$ \\
\hline 1 & 1. A & 1. A & 1. A \\
& 2. B & 2. C & 2. B \\
& 3. C & 3. B & 3. C \\
\hline
\end{tabular}


As for the results of alternative rankings, the use of fuzzy-AHP method is closer to the recommendation given by experts than the use of AHP

\section{Conclusion}

- In this study, we selected the fuzzy AHP degree has been proposed. Decision criteria are religion, property, descent, physical, education, organization marital status, expertise, and rank. This category is evaluated to find the level of preference associated with each alternative to get the most suitable pair for the couple. By using the fuzzy-AHP method, the ambiguity involved in the data can be represented and used to make the process more effective.

- In this study, AHP and FAHP comparative analyzes were presented for multi-criteria of an Islamic couple.

- Using AHP, found that Religion has the highest priority that is 0.4073 while using FAHP has the highest priority that is religion, organization, expertise, status, and rank with weight 0.172848 . As for the results of alternative rankings, the use of fuzzy-AHP method is closer to the recommendation given by experts than the use of AHP.

- The application of fuzzy AHP to the selection of Islamic couple gives different results with conventional AHP, this is because the AHP fuzzy calculation is required a value that is not just one but an optimistic value and a pessimistic value of a value pairwise comparison.

- Fuzzy AHP has advantages that is the level of subjectivity of the retrieval decisions can be accommodated and the lack of AHP fuzzy is the need for information the additional value of optimistic and pessimistic value.

\section{References}

1. A. Aktepe, E. Suleyman, A fuzzy analytic hierarchy process model for supplier selection and a case study, International Journal of Research and Development, 3, 1, 33-37 (2011)

2. A. H. Işı, Ince, M., Yigit, T. A Fuzzy AHP Approach to Select Learning Management System, International Journal of Computer Theory and Engineering, 7, 6, 499 (2015)

3. F. Mulubrhan, A. A. Mokhtar and M. Muhamamed, Comparative Analysis between Fuzzy and traditional Analytical Hierarchy Process, ICPER $4^{\text {th }}$ International Conference on Production, Energy and Reliability (2014)

4. Y. Xia, C. Gang Jiang, An Assessment Model of National Grants of University Based on Fuzzy Analytic Hierarchy Process $3^{\text {rd }}$ Annual International Conference on Information Technology and Applications (2016)

5. R Anggrainingsih, M. Z. Umam, H. Setiadi, Determining e learning success factor in higher education based on user perspective using Fuzzy AHP, MATEC Web Conf.Volume 154. The 2nd
International Conference on Engineering and Technology for Sustainable Development (2017)

6. Lizhen, Zhangruijun, WangChen, Green Degree Comprehensive Evaluation of Elevator Based on Fuzzy Analytic Hierarchy Process. MATEC Web of Conferences Volume 31, $7^{\text {th }}$ International Conference on Mechanical and Electronics Engineering (2015)

7. P. G. W. Keen, M. S. Scott Morton, Decision support systems: An organizational perspective. (Reading, MA: Addison-Wesley, 1978)

8. S. H. Ghodsypour, C. A. O'Brien, Decision Support System for Supplier Selection Using an Integrated Analytic Hierarchy Process and Linear Programming, International Journal of Production Economics, 56-57, 199-212 (1998)

9. Y Tuncay, I Hakan Ali, I. Murat, Multi Criteria Decision Making System for Learning Object Repository, Procedia - Social and Behavioral Sciences 141. 813 - 816 (2014) 